\title{
Synthesis, Spectroscopic Characterization and Photoactivity of Zr(IV) Phthalocyanines Functionalized with Aminobenzoic Acids and Their GO-Based Composites
}

\author{
Leili Tahershamsi ${ }^{1, *} \mathbb{0}$, Yuriy Gerasymchuk ${ }^{1}$, Anna Wedzynska ${ }^{1}$, Maciej Ptak ${ }^{1}$, \\ Iryna Tretyakova ${ }^{2}$ and Anna Lukowiak ${ }^{1}$ \\ 1 Institute of Low Temperature and Structure Research, PAS, ul. Okolna 2, 50-422 Wroclaw, Poland; \\ y.gerasymchuk@intibs.pl (Y.G.); a.wedzynska@intibs.pl (A.W.); m.ptak@intibs.pl (M.P.); \\ a.lukowiak@intibs.pl (A.L.) \\ 2 Institute of General and Inorganic Chemistry, Palladina ave. 32/34, 03142 Kyiv, Ukraine; \\ iryna.tretyakova@gmail.com \\ * Correspondence: 1.tahershamsi@intibs.pl
}

Received: 16 October 2019; Accepted: 17 December 2019; Published: 22 December 2019

\begin{abstract}
Two complexes of bis(aminobenzoato)zirconium(IV) phthalocyanine and their graphite oxide-based composites were synthesized and characterized in respect of their photochemical properties. Structures of phthalocyanines were confirmed by Mass and infrared spectroscopies. The absorption and photoluminescence spectra were investigated to show various behavior of the complexes in different media (dimethyl sulfoxide and saline). Optical technique (monitoring variation of absorption spectra of diphenylisobenzofuran used as an indicator) was used to prove the generation of reactive oxygen species (ROS) by under light irradiation in the range of the first biological window. The photoactivity of the materials was compared and discussed in terms of their potential ability to be used in biomedical applications, for example, as photosensitizers in photodynamic therapy.
\end{abstract}

Keywords: graphite oxide (GO); phthalocyanine complexes; ROS generation; photoluminescence spectroscopy; photodynamic therapy

\section{Introduction}

Due to different abilities of phthalocyanines (Pcs), they have emerged huge interest in catalysis [1], semiconductors, photoconductors [2-4] and optical recording materials [5]. Despite their proficiency in the mentioned area, they are capable of use in medicine as photocytotoxic reagents [6]. Photodynamic therapy (PDT) is a clinically approved procedure for curing cancerous cells, which involves using photosensitizing reagents with the aid of an appropriate wavelength of visible or near infrared (NIR) light $[7,8]$.

Reactive oxygen species (ROS), such as ${ }^{1} \mathrm{O}_{2}, \mathrm{O}_{2}{ }^{-\bullet}, \mathrm{OH}^{\bullet}$ and $\mathrm{H}_{2} \mathrm{O}_{2}$, are responsible for cytotoxic effect which kills injured or microbial cells by a combinatorial effect of light $[9,10]$. Phthalocyanines are one of the most promising candidate in PDT; their role as photosensitizers and their activity in the red-NIR range (the first biological window) and high emission coefficients are not negligible [11-13]. Thus, their photochemical and photobiological properties have been widely reported in the literature [14-16].

Generally, Pcs and MPc complexes (M-Metal) are not soluble in water or dimethyl sulfoxide (DMSO). To use Pcs in pharmacology, good solubility of Pcs in water is preferred $[17,18]$. For this aim, metallophthalocyanines must be functionalized with hydrophilic organic/inorganic substituents 
in lateral position, or small inorganic counter-ions $\left(\mathrm{Cl}^{-}\right.$or $\left.\mathrm{OH}^{-}\right)$or carboxylate groups should be substituted to metal cation of Pc complex in more or less axial position [17]. In our approach, the water solubility of the complexes is achieved by supplemental axial organic ligands attached to the central metal of the complex [19-21]. The choice of metal cation $\left(\mathrm{Zr}^{4+}\right)$ was dictated by the fact that, in zirconium (or hafnium) phthalocyanine complexes, the coordination number of metal is usually 6. After the replacement of simple axial ligands, that is, $\mathrm{Cl}^{-}$and $\mathrm{OH}^{-}$by organic ligands, the coordination number of the metal increases to 8 . Thus, when the complex is formed, metal has 2 additional coordination sites where at least 2 solvent molecules (water, DMSO, dimethylformamide (DMF), etc.) can be bonded. In addition, solubility may be significantly affected by hydrophilic groups present in axial ligands. These two factors cause that the zirconium complexes are relatively well soluble in water and DMSO [18].

Graphene family materials, such as graphene oxide and reduced graphene oxide, have been utilized in a large number of activities in biology field [22-24]. Recent studies showed that, for example, graphene oxide and its reduced forms have antibacterial properties towards Gram-positive, for example, Staphylococcus aureus and Gram-negative, for example, Escherichia coli, bacteria [25,26]. Antibacterial effect of graphene materials could be used to fabricate antimicrobial and biofilm resistant surfaces, for example, polymeric films for biomedical devices [27,28], antibacterial fabric materials [29] and graphene oxide-based membrane for water treatment [30-32]. There are different hypothesis for antibacterial effects of graphene materials. One is driven by spontaneous piercing of the membrane by nanoflakes of carboneous/graphene structures [33]. There is an interaction between basal hydrophobic region of graphene to hydrophobic inner region of plasma of membrane. Inducing cell damage in bacteria by extracting phospholipid molecules from the outer cell membrane [34] and direct oxidation of cellular components by graphene oxide [35] are the other pathways for integration of graphene oxide with bacterial cell membranes. Oxidative stress has another role to deactivate or kill bacteria which might be induced by generation of reactive oxygen species in the presence of graphene structures [35]. Embedding Pcs into graphene or similar nano supports might enhance their photo-physicochemical properties [36]. Macromolecules, such as Pc templates, have tendency to agglomerate in aqueous and biological media, which influence their absorption and emission properties. Due to a dye binding to a graphene carrier, agglomeration of molecules might be significantly reduced. Furthermore, transferring the dye into biological targets such as cells and tissues would be easier and less toxic to biological organisms while they are linked to a carrier [37]. In our previous research, new photosensitive nanomaterial with antibacterial photoactivity were introduced [38], where Pcs derivative was used together with graphene oxide and silver nanoparticles in a composite to enhance the antimicrobial effect.

In this paper we reported synthesis and photochemical characterization of two new zirconium(IV) phthalocyanine derivatives and their graphite oxide-based composites. The absorbance of ZrPcs with aminobenzoate ligands in dimethyl sulfoxide and saline were compared. Absorption spectroscopy was used to determine dependence of absorbance on Pc concentration and singlet oxygen generation under light irradiation for both Pcs and graphite oxide (GO) composites. Photoluminescent properties were also investigated.

\section{Materials and Methods}

\subsection{Materials Syntheses}

\subsubsection{Pc Complexes}

For axial substitution of zirconium (IV) phthalocyanine complex with 4-aminobenzoic acid (PABA) and 3,5-diaminobenzoic acid (DABA), a method described earlier was used [37,39]. Generally, in the first step, dichlorozirconium (IV) phthalocyanine was obtained by template synthesis from phthaliimide (Alfa Aesar, Karlsruhe, Germany) and $\mathrm{ZrCl}_{4}$ (ABCR, Karlsruhe, Germany) in 2-methylnaphtlalene (Alfa Aesar) with heating. $\mathrm{ZrPcCl}_{2}$ was used as a precursor for a next step, where it reacted with 4-aminobenzoic acid (Alfa Aesar) or 3,5-diaminobenzoic acid (Alfa Aesar) in DMSO (Alfa Aesar) during 
heating under reflux for about $6 \mathrm{~h}$. The procedure is schematically shown in Figure 1 . The complexes of bis (4-aminobenzoato) $\mathrm{ZrPc}$ and bis (3,5-diaminobenzoato) $\mathrm{ZrPc}$ were further abbreviated as bis(PABA)ZrPc and bis(DABA)ZrPc, respectively.

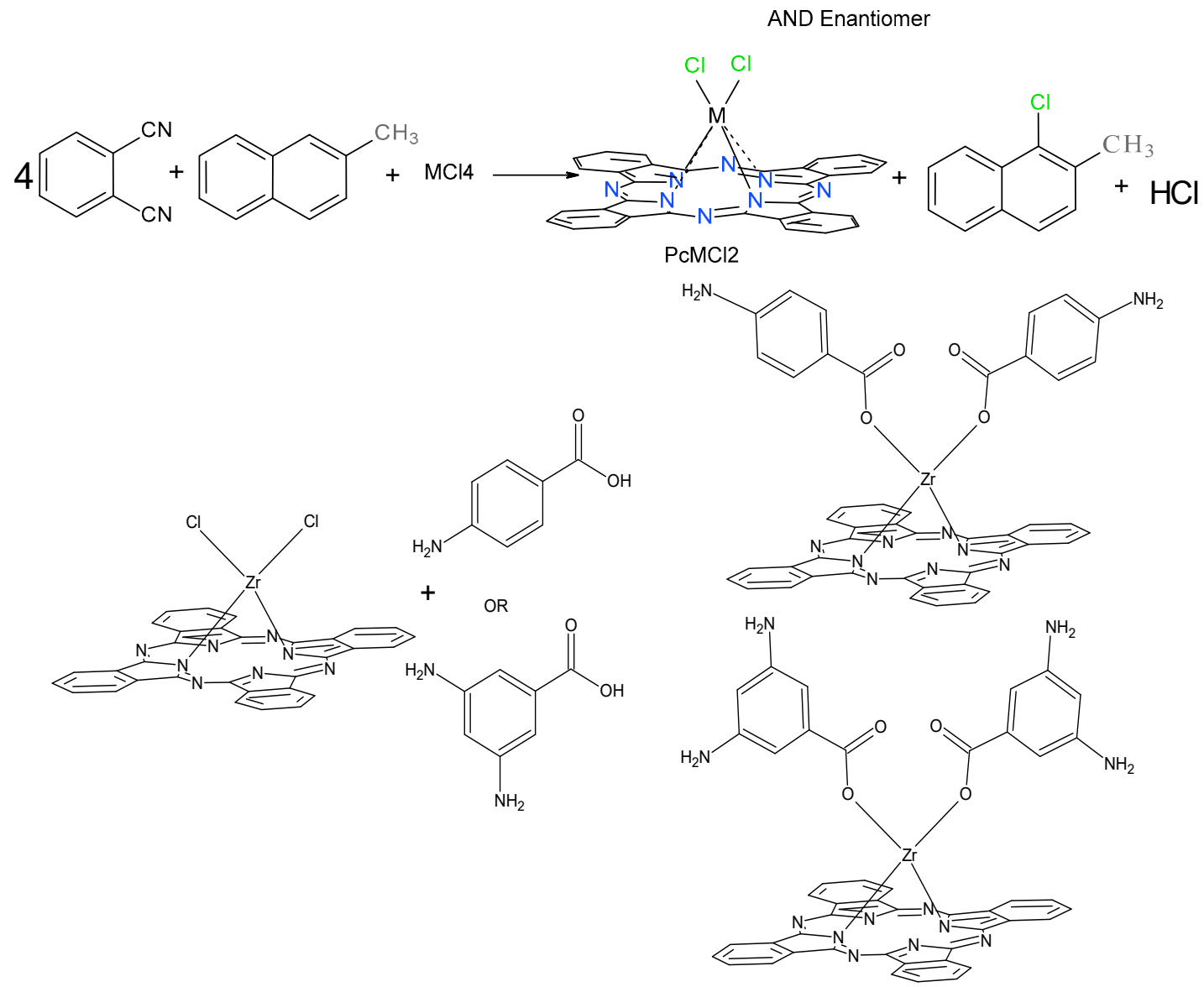

Figure 1. Synthesis of $\mathrm{PcMCl}_{2}$ and bis (L) ZrPc complexes, where zirconium was used as metal ion (M) and 4-aminobenzoic acid (PABA) or 3,5-diaminobenzoic acid (DABA) were used as ligands (L).

\subsubsection{Pc Composites}

Highly oxidized graphite oxide (GO) was prepared according to the modified Brodie method [40] and composite materials were prepared according to a previous report [9]. GO powder (0.5 g) was suspended by ultrasonication $(900 \mathrm{~W}, 22 \mathrm{kHz}$ sonicator) in $5 \mathrm{~mL}$ of dimethylformamide (Alfa Aesar). Then, about $4 \mathrm{mg}$ of bis (L) ZrPc, where L = PABA/DABA correspondingly, was added to the reaction vessel. Reaction mixture was placed in an ice bath and put on a magnetic stirrer. Dicyclohexylcarbodiimide (DCC, $0.06 \mathrm{~g}$ ) (ABCR) was added to the mixture and the reaction was left in the ice bath on the magnetic stirrer for $12 \mathrm{~h}$. After completion of the reaction, bis (L) ZrPc-modified GO materials were separated by centrifuge and washed 3 times with DMF and twice with warm ethanol to remove unreacted dye molecules. Composites were abbreviated as bis(PABA)ZrPc/GO and bis(DABA)ZrPc/GO consecutively.

\subsection{Instrumentation}

A spectrophotometer FLS980 (Edinburgh Instruments, Livingston, UK) with a xenon lamp was used for photoluminescence measurements. The spectra were recorded with the respective lamp and detector corrections. Absorption spectra of Pc solutions and Pc/GO suspensions were measured with a spectrophotometer Agilent CARY 5000 UV-Vis-NIR (Thermo Fisher Scientific, Walham, MA, USA). Polycrystalline IR spectra in the mid-IR region $\left(400-4000 \mathrm{~cm}^{-1}\right)$ were measured using a Nicolet iS50 
FT-IR spectrometer (Thermo Fisher Scientific). The spectral resolution was set to $2 \mathrm{~cm}^{-1}$. A Bruker apex ultra with electrospray ion injector (ESI-MS) (Bruker Optics Inc, Billerica, MA, USA) was used for mass spectroscopy measurements.

\subsection{Materials Characterization}

Structure of complexes were confirmed by ESI-MS analysis and IR spectroscopy. Mass spectra of compounds were recorded in DMF solutions. For FTIR spectra measurements samples were prepared as $\mathrm{KBr}$ pellets. For other optical measurements, stock solutions of ZrPcs in concentration of $0.5 \mathrm{mM}$ were prepared by dissolving the compounds in dimethyl sulfoxide whereas the concentration of composites was about $18 \mathrm{mg} / \mathrm{mL}$. Absorption spectra in the cases of two complexes of phthalocyanines, bis (PABA) ZrPc and bis (DABA) ZrPc, were recorded upon addition of 5 to $45 \mu \mathrm{L}$ of $\mathrm{ZrPc}$ solution to the cuvette containing $2 \mathrm{~mL}$ DMSO and 5 to $125 \mu \mathrm{L}$ of $\mathrm{ZrPc}$ to the cuvette containing $2 \mathrm{~mL} \mathrm{NaCl} \mathrm{aq}_{\mathrm{aq}}$ (9 $\mathrm{mg} / \mathrm{mL}$ ) (the Beer-Lambert experiment, where absorbance versus dye concentration is plotted).

Generation of ${ }^{1} \mathrm{O}_{2}$ upon irradiation was shown by an indirect chemical method, using 1,3-diphenylisobenzofuran (DPBF) as a probe [41]. DPBF reacts with ${ }^{1} \mathrm{O}_{2}$ irreversibly, leading to a decrease in the absorption band at around $420 \mathrm{~nm}$. The solution containing DPBF in DMSO $(20 \mathrm{mg} / \mathrm{mL})$ was prepared on the day of the analysis and stored in the dark. DPBF solution $(14 \mu \mathrm{L})$ was added to a solution of the ZrPc complex ( $20 \mu \mathrm{L}$ of solution in $2 \mathrm{~mL}$ DMSO) (to obtain absorbance level of a measured phthalocyanine solution in Q region around 1) or ZrPc composite (30 $\mu \mathrm{L}$ of suspension in $2 \mathrm{~mL}$ DMSO), which were then irradiated (from $10 \mathrm{~s}$ up to maximum $240 \mathrm{~s}$ ) by red/NIR lamp (Philips, $100 \mathrm{~W}$ ) which served as a light source that was located $30 \mathrm{~cm}$ far from a cuvette. Beer-Lambert graph for bis (PABA) ZrPc was plotted at $683 \mathrm{~nm}$ or $695 \mathrm{~nm}$ at which the absorption bands maxima were registered in DMSO and saline, respectively. For bis (DABA) ZrPc, graph data was registered at $690 \mathrm{~nm}$ and $700 \mathrm{~nm}$ in DMSO and saline, respectively. Photoluminescence and photoluminescence excitation spectra of phthalocyanine complexes were recorded in DMSO at $4 \times 10^{-5} \mathrm{M}$ concentration.

\section{Results}

\subsection{Characterization of Pc Complexes and Composites}

Two different zirconium (IV) phthalocyanines with mono and di-aminobenzoic functionalities axially substituted to the central metal ion and their GO composites were studied in this article (Figure 1). Graphite oxide flakes with dimensions of a few microns and a thickness of several dozen of carbon layers (TEM and SEM images of derived materials are presented in Figure S1 in the Supplementary Materials) and with different oxide groups were used to link functionalized phthalocyanines. To confirm the structures, FTIR and mass spectroscopy measurements were performed. Afterwards, the optical properties of these systems were studied and singlet oxygen generation was examined.

FTIR spectra of bis (PABA) ZrPc and bis (DABA) ZrPc and their composites, bis (PABA) ZrPc/GO and bis (DABA) ZrPc/GO, display expected features (Figure 2), for example, bands at 3464, $3354 \mathrm{~cm}^{-1}$ (Figure 2a) are attributed mainly to amine groups of ligands (Table S1, Supplementary Materials). The broad contour at $3500-3100 \mathrm{~cm}^{-1}$ is related to $\mathrm{OH}$ groups on the GO surface (Figure $2 \mathrm{~b}, \mathrm{~d}$ ). The broad peaks observed in the region of $3500-3100 \mathrm{~cm}^{-1}$ both in complexes and composites, are related to hydrogen bonding of $\mathrm{NH}_{2}$ groups (Figure 2a,c). The narrower bands observed between 2841 and $3081 \mathrm{~cm}^{-1}$ are assigned to stretching vibrations of $\mathrm{CH}$ groups. Strong bands in the $1516-1689 \mathrm{~cm}^{-1}$ region are assigned mainly to stretching vibrations of carbonyl groups $(\mathrm{C}=\mathrm{O})$ coupled to vibrations of aromatic rings and bending vibrations of amine groups in bis (PABA) ZrPc and bis (DABA) ZrPc, respectively. Bending C-O vibrations are assigned to bands observed in the $1207-1288 \mathrm{~cm}^{-1}$. Characteristic stretching vibrations of CNC groups are ascribed to bands observed in the $1207-1458 \mathrm{~cm}^{-1}$ region, while their bending components contribute to many bands in the 505-736 $\mathrm{cm}^{-1}$ and $843-904 \mathrm{~cm}^{-1}$ regions. The bending in-plane vibrations of $\mathrm{CH}$ groups are related to many bands located between 946 and $1386 \mathrm{~cm}^{-1}$, while out-of-plane aromatic $\mathrm{CH}$ are observed at lower wavenumbers $\left(417-904 \mathrm{~cm}^{-1}\right)$. 
The characteristic stretching vibrations of rings in Pc are assigned to bands between 1102 and $1600 \mathrm{~cm}^{-1}$. The in- and out-of-plane bending vibrations of rings contribute to bands observed in the $505-1088 \mathrm{~cm}^{-1}$ and 417-830 $\mathrm{cm}^{-1}$, respectively [42] (Figure 2a). The characteristic bands of GO are clearly visible at 1068,1612 and $1724 \mathrm{~cm}^{-1}$ for bis (PABA) $\mathrm{ZrPc} / \mathrm{GO}$ and at $983,1071,1612$ and $1725 \mathrm{~cm}^{-1}$ for bis (DABA) $\mathrm{ZrPc} / \mathrm{GO}[43]$.
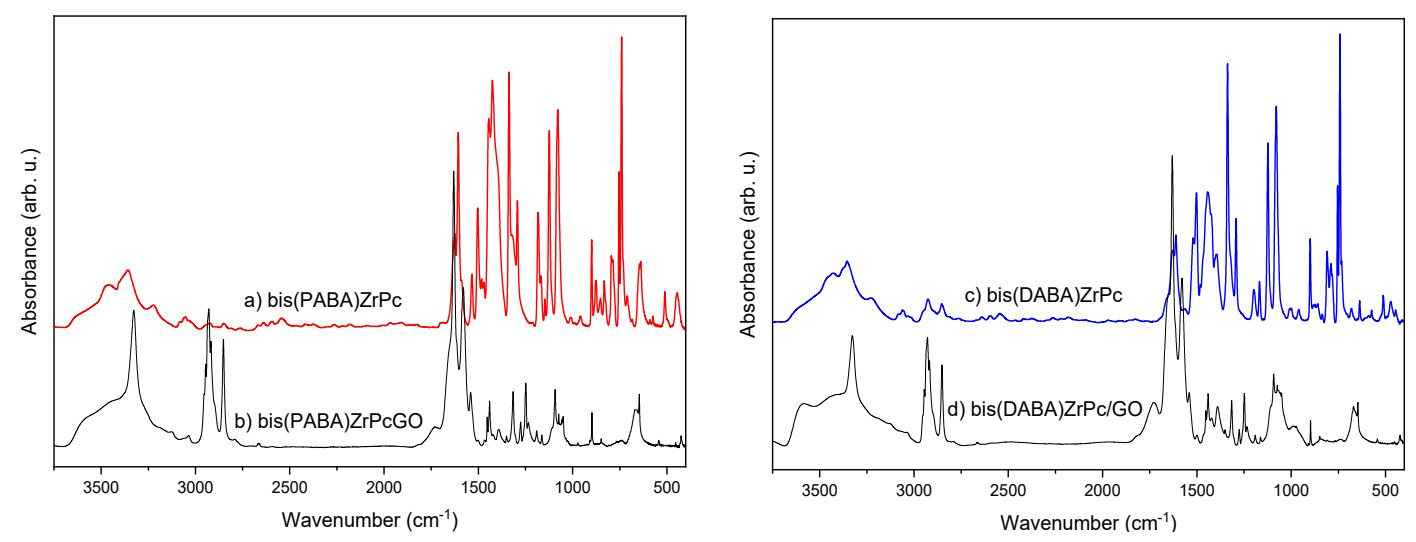

Figure 2. Fourier-transform infrared (FTIR) spectra of (a) bis (PABA) ZrPc, (b) bis (PABA) ZrPc/GO, (c) bis (DABA) ZrPc and (d) bis (DABA) ZrPc/GO.

By coupling reaction between phthalocyanine and GO, new linkages (amide bonds; Pc-NH-CO-GO) are formed in the system. Therefore, new peaks related to amide bonds are expected in the FTIR spectra of composites [44]. Three distinct differences can be found in FTIR spectra of composites that confirm the amide bond formation in the composites: (i) decrease in intensity of bands corresponding to $\mathrm{NH}_{2}$ stretching vibrations (Figure 2a,c); (ii) appearance of one narrow peak at $3325 \mathrm{~cm}^{-1}$ in bis (PABA) ZrPc/GO and $3326 \mathrm{~cm}^{-1}$ in (bis (DABA) ZrPc/GO spectra (Figure 2b,d); (iii) and the increase of intensity and shifts of bands corresponding to the stretching vibrations of carbonyl $(\mathrm{C}=\mathrm{O})$ groups of amides at $1626 \mathrm{~cm}^{-1}$ in both composites (Figure 2a,c).

Mass spectroscopy analysis confirmed the structure of Pc complexes. In ESI-MS spectra of phthalocyanine complexes (Figure S2, Supplementary Materials), peaks with the molecular mass more than exact mass of complex could be seen due to one or two molecules of solvent (DMF) extracoordinated to metal atom of phthalocyanine complex as presented for bis (PABA) ZrPc in Figure 3. Coordinated solvent molecules are bonded more strongly with metal atom than axial ligand. Moreover, as it is shown in Figure 3, the structure breaks in ionization chamber of the spectrometer. Fragmentation starts with removal of amine functionalities from the ligand followed by detachment of phenone groups from the ZrPc structure. In this step, two molecules of DMF are bonded to the structure which will be removed later during ionization process. In the case of bis (DABA) ZrPc, the ESI-MS analysis give a molecular ion peak at $m / z \sim 908$. In the case of bis (DABA) ZrPc bonded to one molecule of DMF (bis (DABA) ZrPc+DMF), peak at $m / z \sim 981$ is observed. Signal at $m / z \sim 950$ corresponds to the complex with one molecule of the solvent (DMF) while two amino groups are detached from the structure (bis (DABA) ZrPc+DMF-2NH $\mathrm{NH}_{2}$. The signal at $m / z \sim 880$ relates to the loss of two amino groups in bis (DABA) ZrPc complex. In ESI-MS, there is a possibility of formation of radical cations; especially easily oxidizable compounds, for example, hydrocarbon polyenes, polycyclic aromatic hydrocarbons, porphyrins and so forth. The ions observed by mass spectroscopy are quasimolecular ions created by the addition of a hydrogen cation $[\mathrm{M}+\mathrm{H}]^{+}$or another cation, for example, Na denoted as $[\mathrm{M}+\mathrm{Na}]^{+}[45]$. 


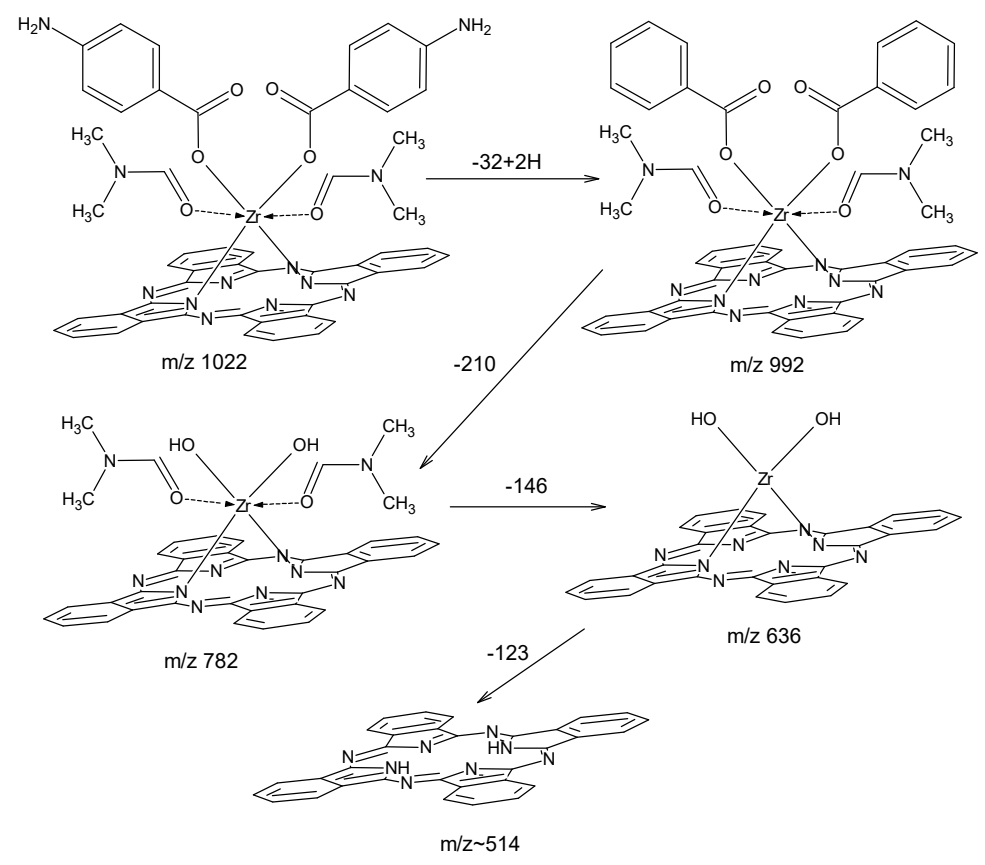

Figure 3. Fragmentation pattern of phthalocyanine complexes according to ESI-MS analysis.

\subsection{Spectroscopic Studies and Singlet Oxygen Generation}

Optical properties of Pc complexes and composites were studied in two media (DMSO and saline-solution of sodium chloride in water). DMSO and saline were chosen for their compatibility in biological systems.

In the UV-Vis-NIR absorption spectra of MPcs, two specific regions are expected. Soret (or B) band usually is seen in the range between $300-400 \mathrm{~nm}$. Band in the region between 620-750 nm named Q band is another characteristic feature. Both are seen in the spectra of the studied complexes. The intense absorption is visible at $345 \mathrm{~nm}$ (B band) and $685 \mathrm{~nm}$ (Q band) for both Pcs in DMSO (Figure 4a). Satellite peak is seen at $618 \mathrm{~nm}$. Similar positions of the bands are seen for Pc complexes in saline-B band at $340 \mathrm{~nm}, \mathrm{Q}$ band at $695 \mathrm{~nm}$ and satellite peak at $640 \mathrm{~nm}$ (Figure $4 \mathrm{~b}$ ). In transition metal complexes, these bands result from transition of electrons in molecular orbitals ( $\mathrm{d}-\mathrm{d}$ transitions). $\mathrm{B}$ band arise due to deeper $\pi-\pi^{*}$ transitions and Q band is attributed to the $\pi-\pi^{*}$ transition from HOMO to LUMO of Pc rings. Change of shape of the $Q$ band and shift of band maxima (main and satellite) correspond with face-to-face dimerization of phthalocyanine complexes in water solution and conjugation of $\pi$-electron systems of two macrocycles.

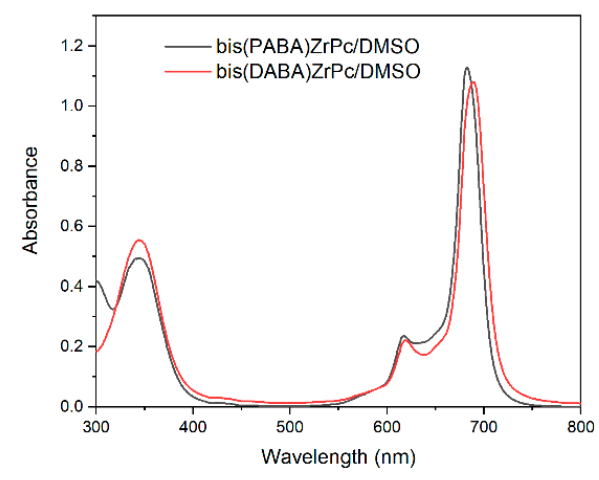

(a)

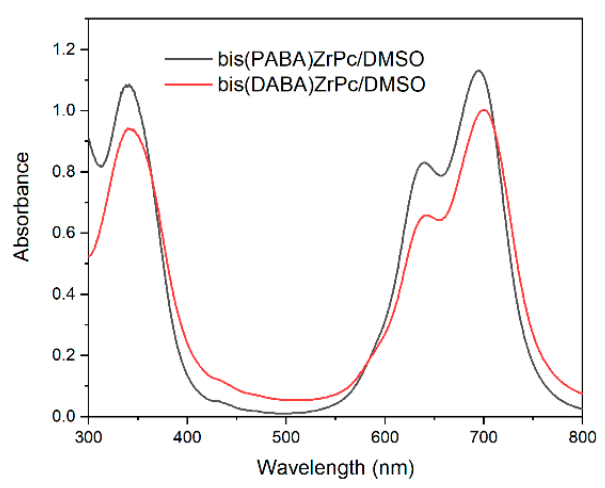

(b)

Figure 4. Absorption spectra of studied phthalocyanine complexes in (a) dimethyl sulfoxide (DMSO) and $(\mathbf{b})$ saline. Molar concentration $=2 \times 10^{-5} \mathrm{M}$. 
The absorption spectra were also registered for different concentrations of complexes in DMSO or saline. The concentration of $\mathrm{ZrPcs}$ in DMSO was chosen to not exceed the value of $\mathrm{Q}$ band absorbance above 2.2 and the maximum concentration in saline used during experiment was about three times higher than in DMSO. The obtained spectra with the graphs showing the dependence of absorbance (at selected wavelength) on $\mathrm{ZrPc}$ concentrations are presented in Figure 5; Figure 6.

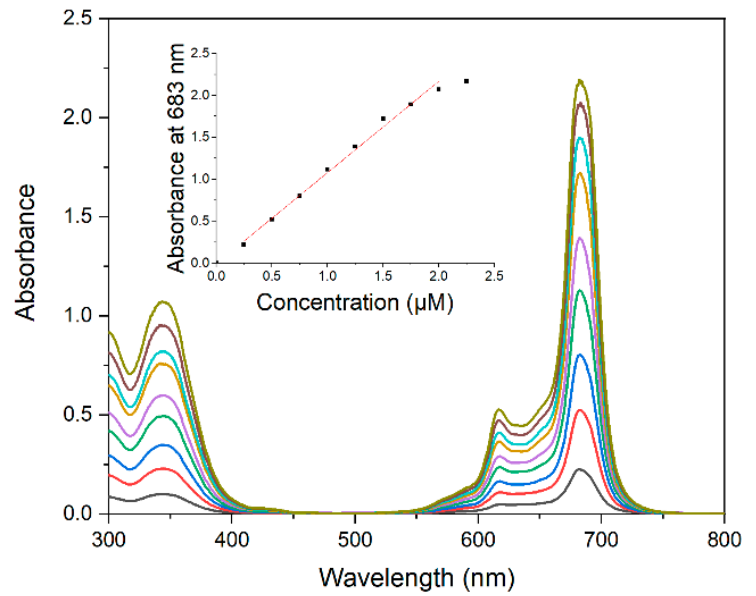

(a)

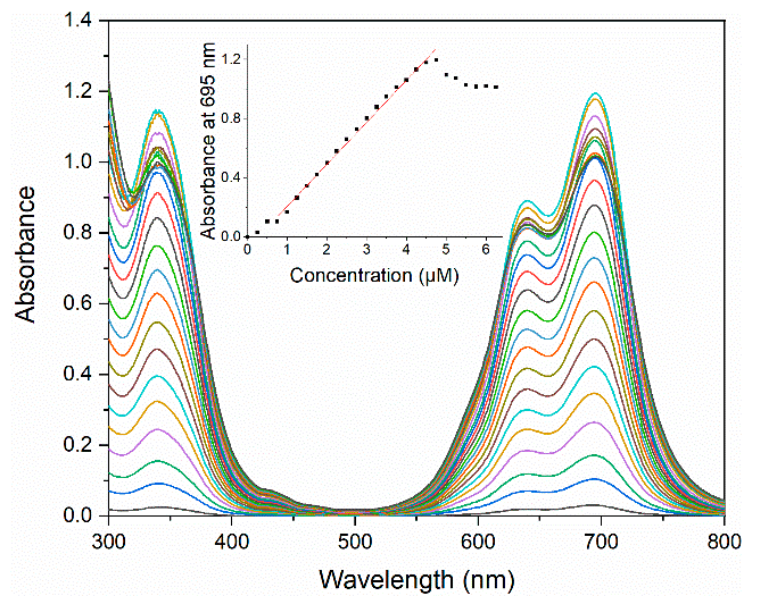

(b)

Figure 5. Absorption spectra of different concentrations of bis(PABA)ZrPc in (a) DMSO (from 0.25 to $2.2 \mu \mathrm{M}$ ) and (b) saline (from 0.25 to $6.0 \mu \mathrm{M}$ ) and the results of Beer-Lambert linearity experiment (insets).

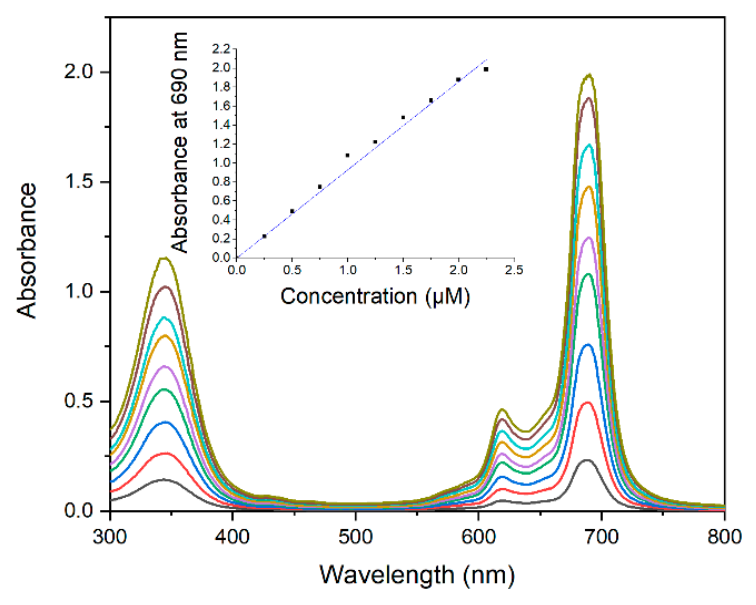

(a)

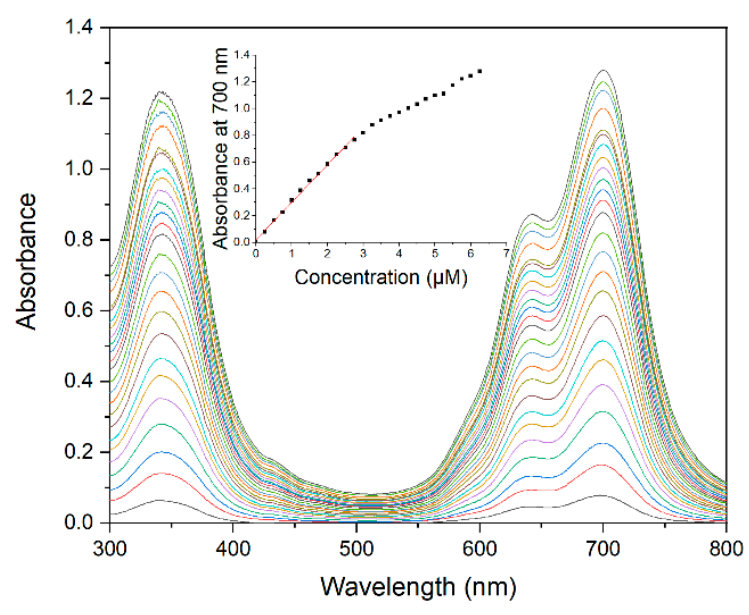

(b)

Figure 6. Absorption spectra of different concentrations of bis(DABA)ZrPc in (a) DMSO (from 0.25 to $2.2 \mu \mathrm{M}$ ) and (b) saline (from 0.25 to $6.0 \mu \mathrm{M}$ ) and the results of Beer-Lambert linearity experiment (insets).

Capability of the complexes and composites as photosensitizers for singlet oxygen generation under irradiation was examined with 1,3-diphenylisobenzofuran which is a well-known reagent for this purpose. Absorption spectra of Pc complexes and composites in DMSO were recorded before and after addition of DPBF (Figures 7 and 8). Decrease of the DPBF absorbance (bleaching) $\left(\lambda_{\max }=418 \mathrm{~nm}\right.$ ) in the presence of $\mathrm{ZrPc}$ complexes and composites was registered under different time of lamp irradiation. 


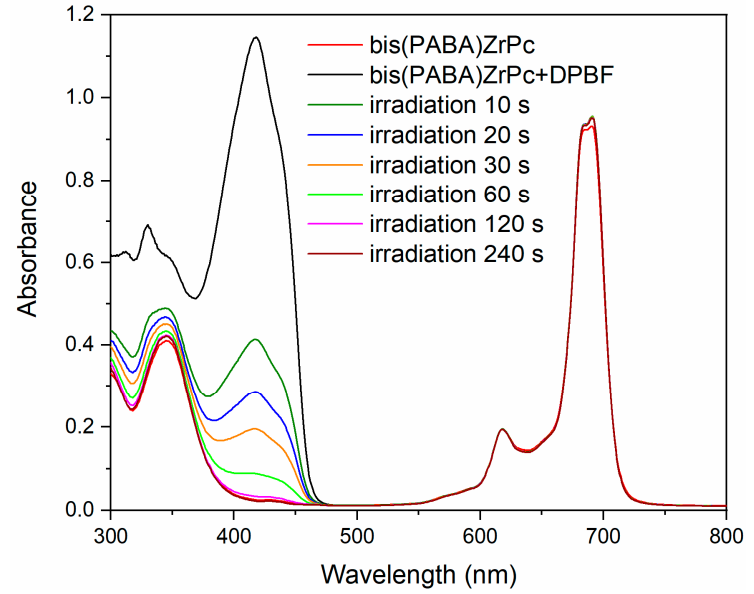

(a)

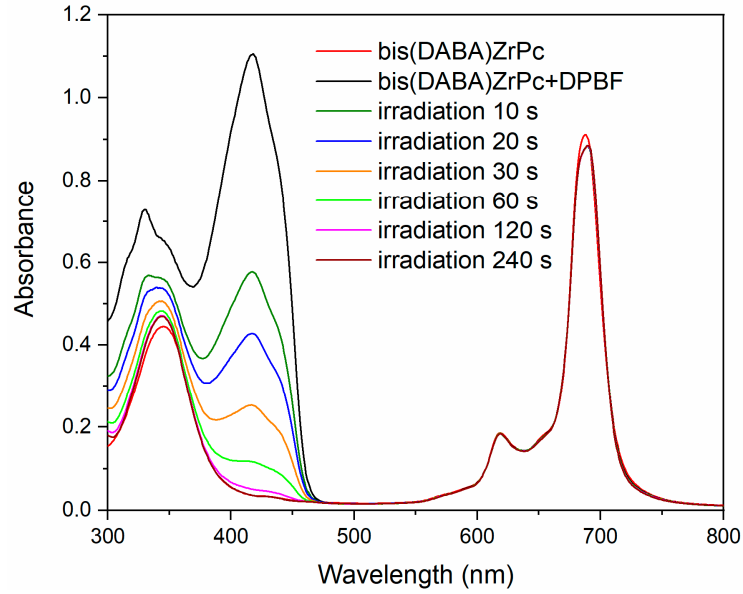

(b)

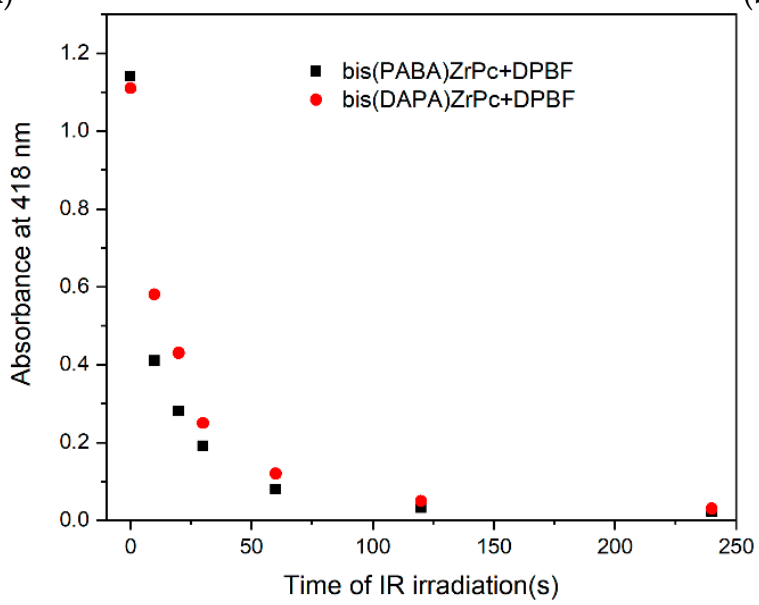

(c)

Figure 7. Absorption spectra of (a) bis (PABA) ZrPc and (b) bis (DABA) ZrPc solutions in DMSO before and after addition of 1,3-diphenylisobenzofuran showing DPBF bleaching when exposed to light irradiation (due to singlet oxygen generation). (c) Irradiation time dependence of DPBF absorbance in the presence of $\mathrm{ZrPcs}$.

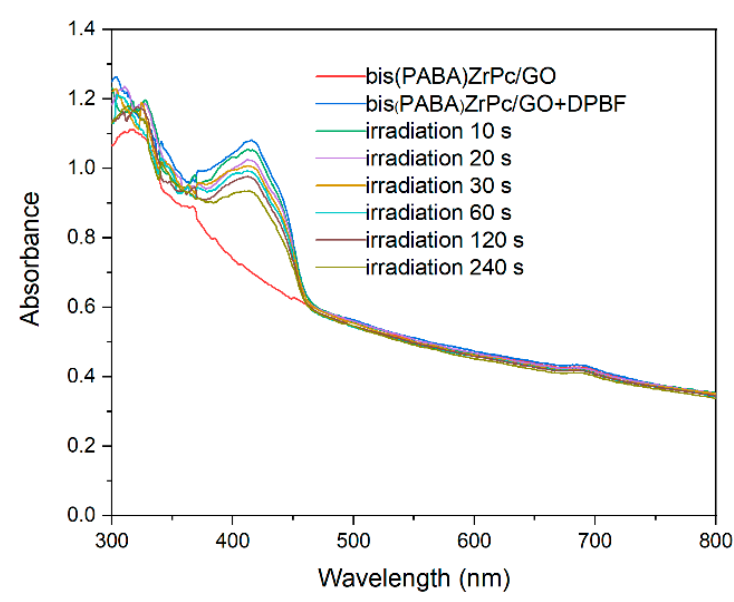

(a)

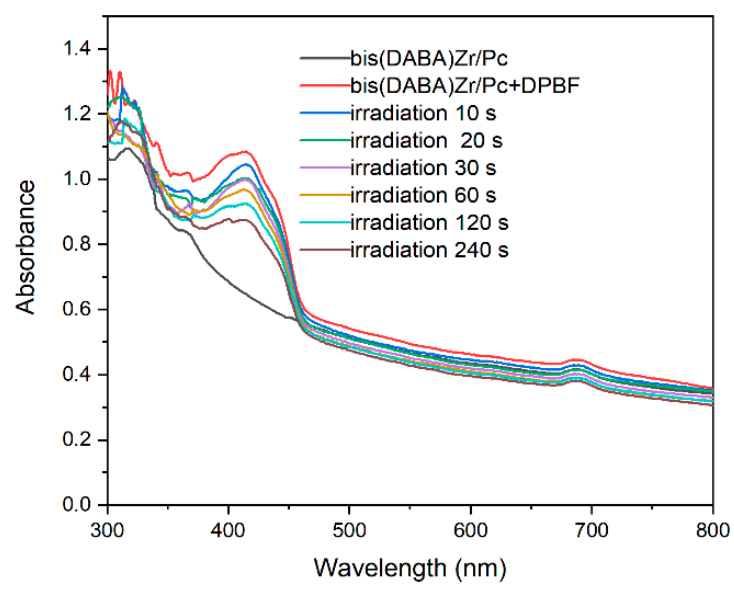

(b)

Figure 8. Cont. 


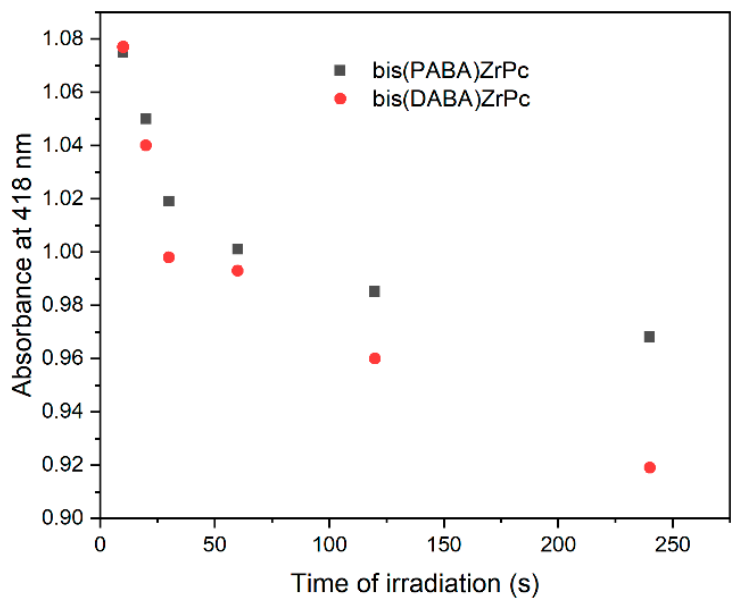

(c)

Figure 8. Absorption spectra of (a) bis (PABA) $\mathrm{ZrPc} / \mathrm{GO}$ and (b) bis (DABA) $\mathrm{ZrPc} / \mathrm{GO}$ suspensions before and after addition of 1,3-diphenylisobenzofuran showing DPBF bleaching when exposed to light irradiation. (c) Irradiation time dependence of DPBF absorbance in the presence of $\mathrm{ZrPc} / \mathrm{GO}$ composites.

Photoluminescence excitation and emission spectra of bis (PABA) ZrPc and bis (DABA) ZrPc in DMSO are shown in Figure 9. The photoluminescence excitation spectra were recorded monitoring the maximum of $\mathrm{ZrPc}$ emission band at $704 \mathrm{~nm}$. Like in the case of absorption spectrum, two broad bands were observed: one in the range of 300-400 nm and the second one above $550 \mathrm{~nm}$ (here, only the satellite band around $620 \mathrm{~nm}$ was recorded). To avoid an overlap of emission band and excitation wavelength, the $620 \mathrm{~nm}$ excitation was used (instead of $690 \mathrm{~nm}$ where the maximum of Q band occurs). In the luminescence spectra, characteristic broad band in the range of 670-800 nm was observed. The measurement conditions did not allow to register spectra of complexes in saline nor composites.

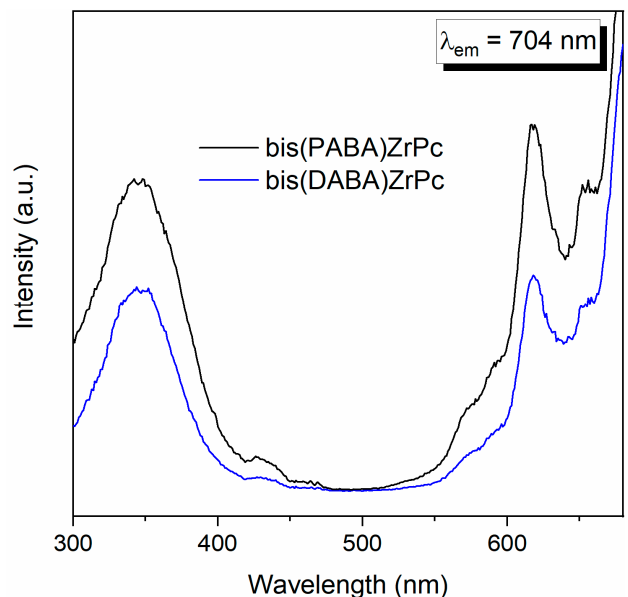

(a)

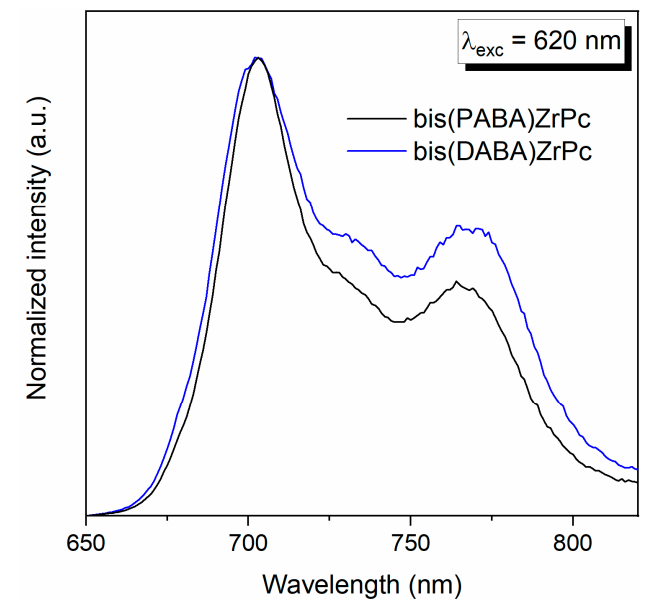

(b)

Figure 9. (a) Photoluminescence excitation $\left(\lambda_{\mathrm{em}}=704 \mathrm{~nm}\right)$ and $(\mathbf{b})$ photoluminescence spectra $\left(\lambda_{\mathrm{exc}}=\right.$ $620 \mathrm{~nm}$ ) of bis (PABA) ZrPc and bis (DABA) ZrPc in DMSO.

\section{Discussion}

Dimerization, higher order association and self-aggregation of Pc rings usually take place in polar environments (polar solvents) that affects photochemical and photo physical properties of Pcs, for example, absorption intensity of complexes decrease during dimerization of metal phthalocyanine complexes. UV-Vis-NIR spectroscopy is a suitable mean to study this effect [46]. Shifts in Q band and changes in shape of this band indicate aggregation processes. In order to utilize Pcs in biomedicine, metal 
phthalocyanines should have good solubility without aggregation in polar solvents [46]. Therefore, aggregation properties of the obtained complexes were studied at different concentration range $(0.25-2.25 \mu \mathrm{M})$ in DMSO and $(0.25-6.25 \mu \mathrm{M})$ in saline.

First of all, the registered absorption spectra of the complexes are common for metal phthalocyanines in non-polar (DMSO) and polar (saline) solvents showing different width and relative intensities of the bands. Shape of the spectra shown in Figures $5 b$ and $6 b$ resulted from dimerization of Pc structures in aqueous solution. Looking at the spectra registered for various $\mathrm{ZrPc}$ concentrations, the findings were in agreement with Beer-Lambert law linearity experiment in DMSO showing that there is no clear evidence of molecules aggregation (dimerization and further agglomeration) in this solvent for the studied concentration range (insets in Figures 5a and 6a). The same should be for other organic solvents as verified in our earlier works [20,21]. In case of using saline solution for both complexes, deviation from Beer-Lambert linearity law was observed for ZrPc concentration higher than 4 and $3 \mu \mathrm{M}$, for bis (PABA) $\mathrm{ZrPc}$ and bis (DABA) $\mathrm{ZrPc}$, respectively (insets in Figures $5 b$ and $6 b$ ). Non-linear dependence indicated clearly high degree of molecules aggregation. Lower concentration limit for bis (DABA) ZrPc may be observed due to higher polarity of DABA ligands (higher tendency to dimerization than in the case of PABA) [20]. Eventually, in the spectra of GO-based structures functionalized with ZrPc derivatives, weak bands at around $690 \mathrm{~nm}$ were seen (Figure $8 \mathrm{a}, \mathrm{b}$ ) confirming the presence of phthalocyanines in the composites.

Photoluminescence excitation spectra (Figure 9) showed that two ranges of light wavelengths can be used for samples excitations, that is, UV/blue and red/NIR. Red (here $620 \mathrm{~nm}$ ) excitation confirmed the presence of red/NIR luminescence of ZrPc complexes. Photoluminescence was not recorded for complexes in saline or for composites. In the first case, the aggregation of $\mathrm{ZrPc}$ might be the reason for low luminescence properties. In the case of composites, low content of $\mathrm{ZrPc}$ on GO flakes (as indicated by the absorption spectra) would explain lack of seen light emission.

Broadband red/NIR light emitting lamp was used for singlet oxygen generation tests. This commercially available light source was suitable for $\mathrm{ZrPcs}$ photoactivation. Both phthalocyanine complexes produced reactive oxygen species with similar effectiveness (Figure 7). The DPBF absorption band was not seen after 2 min of irradiation.

Despite the fact that the concentration of Pcs was much lower in the composites than in the solutions, singlet oxygen generation was still observed for these samples but the amount of reactive species was not enough high to react with the DPBF molecules after 4 min of irradiation. Nevertheless, the idea to link chosen Pcs to a GO carrier and to maintain their photoactivities was proved to be correct. The results shown in Figure 8c marked that the activity of bis (DABA) ZrPc/GO is slightly higher (faster DPBF bleaching). Differences in the amount of ${ }^{1} \mathrm{O}_{2}$ generated by bis (L) ZrPcs may depend on their structure. Bis (PABA) ZrPc with two amino groups of two ligands is geometrically favorable (less hindrance for para position) but bis (DABA) ZrPc, with four amino groups in meta position, provides better connection/linkage to graphite oxide as support (mainly due to the possibility to form more hydrogen bonding but also through $\pi-\pi$ stacking or covalent bonding to carrier surface). To increase the photoactivity of composites, one could think of loading more of Pc complexes on the GO structure. In this study, synthesis of composites was already performed in a way to ensure relatively high concentration of $\mathrm{ZrPc}$ and it would be difficult to obtain higher phthalocyanine content. But it must be noted that structure of complexes with different functionalities absolutely affects the attachment process that further influence on the ${ }^{1} \mathrm{O}_{2}$ generation as reported in our previous studies of other ligands bonded to $\mathrm{ZrPc}[38,47]$.

In conclusion, the generation of singlet oxygen has been a subject of great interest in different disciplines, from polymer science to medicine. High chemical reactivity of singlet oxygen can be utilized in biological systems, for example, in PDT [48] including antiseptic effect. Photoactivity capacity of the studied materials (both complexes and composites) was proved by the test of singlet oxygen generation using DPBF. Comparison between complexes and composites showed better ${ }^{1} \mathrm{O}_{2}$ generation in ZrPcs. From excitation and emission spectra of Pc complexes, one could conclude that 
these phthalocyanine compounds are good candidates for PDT photosensitizers, since excitation at 600-700 $\mathrm{nm}$ and emission between 700-800 $\mathrm{nm}$ are essential to penetrate deep enough into tissues [38].

Supplementary Materials: The following are available online at http://www.mdpi.com/2311-5629/6/1/1/s1, Figure S1: TEM and SEM images of graphite oxide flakes with zirconium(IV) phthalocyanine derivatives; Figure S2: Mass spectra of (a) bis (PABA) ZrPc, (b) bis (DAPA) ZrPc; Table S1: IR wavenumbers and relative intensities of observed bands together with proposed assignment for the studied complexes and composites.

Author Contributions: Conceptualization, Y.G. and A.L., methodology, L.T., Y.G. and I.T., investigation, L.T., Y.G., A.W., M.P. and A.L.; writing-original draft preparation, L.T.; writing-review and editing, L.T., Y.G., M.P. and A.L.; visualization, L.T., Y.G. and A.L. supervision, Y.G. and A.L.; project administration, A.L.; funding acquisition, Y.G and A.L. All authors have read and agreed to the published version of the manuscript.

Funding: This research was funded by National Science Centre research grant No. 2016/23/B/ST5/024830.

Conflicts of Interest: The authors declare no conflict of interest.

\section{References}

1. Jones, R.; Davidson, K.; Krier, A. Structure, electrical conductivity and electrochromism in thin films of substituted and unsubstituted lanthanide bisphthalocyanines. Thin Solid Film 1997, 298, 228-236. [CrossRef]

2. Duarte, J.P.; Vilao, R.C.; Gil, J.M.; Alberto, H.V.; de Campos, N.A.; Weidinger, A. Muoniated radicals in the organic semiconductor zinc-phthalocyanine. Physica B 2003, 326, 94-96. [CrossRef]

3. Tada, H.; Touda, H.; Takada, M.; Matsushige, K. Quasi-intrinsic semiconducting state of titanyl-phthalocyanine films obtained under ultrahigh vacuum conditions. Appl. Phys. Lett. 2000, 76, 873-875. [CrossRef]

4. Peisert, H.; Knupfer, M.; Schwieger, T.; Auerhammer, J.M.; Golden, M.S.; Fink, J. Full characterization of the interface between the organic semiconductor copper phthalocyanine and gold. J. Appl. Phys. 2002, 91, 4872-4878. [CrossRef]

5. Drobizhev, M.; Rebane, A.; Spahni, H.; Spangler, W.; Wolleb, H. Two Photon or Multiphoton Phthalocyanine Based Absorption Material for Optical Data Storage. European Patent Pub. No. WO/2007/014849, 8 February 2007. Available online: https://patentscope.wipo.int/search/en/detail.jsf?docId=WO2007014849\& tab=PCTBIBLIO (accessed on 22 December 2019).

6. $\mathrm{Li}, \mathrm{X} . ; \mathrm{Ng}$, D.K.P. Synthesis and spectroscopic properties of the first phthalocyanine-nucleobase conjugates. Tetrahedron Lett. 2001, 42, 305-309. [CrossRef]

7. Dolmans, D.E.; Fukumura, D.; Jain, R.K. Photodynamic therapy for cancer. Nat. Rev. Cancer 2003, 3, 380-387. [CrossRef]

8. Josefsen, L.B.; Boyle, R.W. Photodynamic therapy: Novel third-generation photosensitizers one step closer. Br. J. Pharmacol. 2008, 154, 1-3. [CrossRef]

9. Sharman, W.M.; Allen, C.M.; van Lier, J.E. Role of activated oxygen species in photodynamic therapy. Methods Enzymol. 2000, 319, 376-400. [CrossRef]

10. MacDonald, I.J.; Dougherty, T.J. Basic principles of photodynamic therapy. J. Porphyrins Phthalocyanines 2001, 5, 105-129. [CrossRef]

11. Allen, C.M.; Sharman, W.M.; van Lier, J.E.J. Current status of phthalocyanines in the photodynamic therapy of cancer. J. Porphyryns Phthalocyanines 2001, 5, 161-169. [CrossRef]

12. Yslas, E.I.; Durantini, E.N.; Rivarola, V.A. Zinc-(II) 2,9,16,23-tetrakis (methoxy) phthalocyanine: Potential photosensitizer for use in photodynamic therapy in vitro. Bioorg. Med. Chem. 2007, 15, 4651-4660. [CrossRef] [PubMed]

13. Vittar, N.B.R.; Awruch, J.; Azizuddin, K.; Rivarola, V. Caspase-independent apoptosis, in human MCF-7c3 breast cancer cells, following photodynamic therapy, with a novel water-soluble phthalocyanine. Int. J. Biochem. Cell Biol. 2010, 42, 1123-1131. [CrossRef] [PubMed]

14. Li, D.; Diao, J.; Wang, D.; Liu, J.; Zhang, J. Design, synthesis and biological evaluation of folate-porphyrin: A new photosensitizer for targeted photodynamic therapy. J. Porphyrins Phthalocyanines 2010, 14, 547-555. [CrossRef] 
15. Pereira, M.M.; Monteiro, C.J.P.; Simoes, A.V.C.; Pinto, S.M.A.; Arnaut, L.G.; Sa, G.F.F.; Silva, E.F.F.; Rocha, L.B.; Simoes, S.; Formosinho, S.J. Synthesis and photophysical properties of amphiphilic halogenated bacteriochlorins: New opportunities for photodynamic therapy of cancer. J. Porphyrins Phthalocyanines 2009, 13, 567-573. [CrossRef]

16. Rani-Beeram, S.; Meyer, K.; McCrate, A.; Hong, Y.; Nielsen, M.; Swavey, S. A Fluorinated ruthenium porphyrin as a potential photodynamic therapy agent: Synthesis, characterization, DNA binding, and melanoma Cell Studies. Inorg. Chem. 2008, 47, 11278-11283. [CrossRef]

17. Ejsmont, K.; Kubiak, R. (1,2-Benzenedicarbonitrile- $k \mathrm{~N})$ diiodo-(phthalocyaninato- $k 4 \mathrm{~N})$ zirconium(IV). Acta Cryst. C 1998, 54, 572-574. [CrossRef]

18. Tomachynski, L.A.; Chernii, V.Y.; Volkov, S.V. Synthesis and properties of axially substituted zirconium(IV) and hafnium(IV) phthalocyanines with organic ligands. J. Porphyrins Phthalocyanines 2001, 5, 731-734. [CrossRef]

19. Gerasymchuk, Y.; Volkov, S.; Chernii, V.; Tomachynski, L.; Radzki, S. Synthesis and spectral properties of axially substituted zirconium(IV) and hafnium(IV) water soluble phthalocyanines in solutions. J. Alloys Compd. 2004, 380, 186-190. [CrossRef]

20. Gerasymchuk, Y.; Chernii, V.; Tomachynski, L.; Kowalska, M.; Legendziewicz, J.; Radzki, S. Correlation between computer models of structure of 5-sulfosalicylato $\mathrm{Zr}(\mathrm{IV})$ phthalocyanine with results obtained by NMR, ESI-MS and UV-Vis spectra. Opt. Mater. 2010, 32, 1193-1201. [CrossRef]

21. Tomachynski, L.A.; Tretyakova, I.; Chernii, V.; Kowalska, M.; Volkov, S.V.; Gerasymchuk, Y.; Radzki, S. Synthesis and spectral properties of $\mathrm{Zr}(\mathrm{IV})$ and $\mathrm{Hf}(\mathrm{IV})$ phthalocyanines with $\beta$-diketonates as axial ligands. Inorg. Chim. Acta 2008, 361, 2569-2581. [CrossRef]

22. Hao, X.; Chen, S.; Zhu, H.; Wang, L.; Zhang, Y.; Yin, Y. The synergy of graphene oxide and polydopamine assisted immobilization of lysozyme to improve antibacterial properties. Chem. Sel. 2017, 2, $2174-2182$. [CrossRef]

23. Hao, X.; Chen, S.; Yu, H.; Liu, D.; Sun, W. Metal ion-coordinated carboxymethylated chitosan grafted carbon nanotubes with enhanced antibacterial properties. RSC Adv. 2016, 6, 39-43. [CrossRef]

24. Hao, X.; Chen, S.; Wang, W.; Yang, Z.; Yue, L.; Sun, H.; Cheng, F. Ag NP-coordinated glucosamine-grafted carbon nanotubes with enhanced antibacterial properties. New J. Chem. 2017, 41, 7045-7051. [CrossRef]

25. Akhavan, O.; Ghaderi, E. Toxicity of graphene and graphene oxide nanowalls against bacteria. ACS Nano 2010, 4, 5731-5736. [CrossRef]

26. Hu, W.B.; Peng, C.; Luo, W.J.; Lv, M.; Li, X.M.; Li, D.; Huang, Q.; Fan, C.H. Graphene-based antibacterial paper. ACS Nano 2010, 4, 4317-4323. [CrossRef]

27. Carpio, I.E.M.; Santos, C.M.; Wei, X.; Rodrigues, D.F. Toxicity of a polymer-graphene oxide composite against bacterial planktonic cells, biofilms, and mammalian cells. Nanoscale 2012, 4, 4746-4756. [CrossRef]

28. Mazaheri, M.; Akhavan, O.; Simchi, A. Flexible bactericidal graphene oxide-chitosan layers for stem cell proliferation. Appl. Surf. Sci. 2014, 301, 456-462. [CrossRef]

29. Karimi, L.; Yazdanshenas, M.E.; Khajavi, R.; Rashidi, A.; Mirjalili, M. Using graphene/ $\mathrm{TiO}_{2}$ nanocomposite as a new route for preparation of electroconductive, self-cleaning, antibacterial and antifungal cotton fabric without toxicity. Cellulose 2014, 21, 3813-3827. [CrossRef]

30. Mi, B.X. Graphene oxide membranes for ionic and molecular sieving. Science 2014, 343, 740-742. [CrossRef]

31. Hu, M.; Mi, B.X. Layer-by-layer assembly of graphene oxide membranes via electrostatic interaction. J. Membr. Sci. 2014, 469, 80-87. [CrossRef]

32. Joshi, R.K.; Carbone, P.; Wang, F.C.; Kravets, V.G.; Su, Y.; Grigorieva, I.V.; Wu, H.A.; Geim, A.K.; Nair, R.R. Precise and ultrafast molecular sieving through graphene oxide membranes. Science 2014, 343, 752-754. [CrossRef] [PubMed]

33. Li, Y.F.; Yuan, H.Y.; von dem Bussche, A.; Creighton, M.; Hurt, R.H.; Kane, A.B.; Gao, H.J. Graphene microsheets enter cells through spontaneous membrane penetration at edge asperities and corner sites. Proc. Natl. Acad. Sci. USA 2013, 110, 12295-12300. [CrossRef] [PubMed]

34. Seabra, A.B.; Paula, A.J.; de Lima, R.; Alves, O.L.; Duran, N. Nanotoxicity of graphene and graphene oxide. Chem. Res. Toxicol. 2014, 27, 159-168. [CrossRef] [PubMed]

35. Liu, S.; Zeng, T.H.; Hofmann, M.; Burcombe, E.; Wei, J.; Jiang, R.R.; Kong, J.; Chen, Y. Antibacterial activity of graphite, graphite oxide, graphene oxide, and reduced graphene oxide: Membrane and oxidative stress. ACS Nano 2011, 5, 6971-6980. [CrossRef] 
36. Zou, J.L.; Chen, X.L. Using silica nanoparticles as a catalyst carrier to the highly sensitive determination of thiamine. Microchem. J. 2007, 86, 42-47. [CrossRef]

37. Tomachynski, L.A.; Chernii, V.Y.; Volkov, S.V. Synthesis of dichlorophthalocyaninato complexes of titanium, zirconium, and hafnium. Russ. J. Inorg. Chem. 2002, 47, 254-257.

38. Gerasymchuk, Y.; Lukowiak, A.; Wedzynska, A.; Kedziora, A.; Bugla-Ploskonska, G.; Piatek, D.; Bachanek, T.; Chernii, V.; Tomachynski, L.; Strek, W. New photosensitive nanometric graphite oxide composites as antimicrobial material with prolonged action. J. Inorg. Biochem. 2016, 159, 142-148. [CrossRef]

39. Tomachynski, L.A.; Chernii, V.Y.; Gorbenko, H.N.; Filonenko, V.V.; Volkov, S.V. Synthesis, spectral properties, and antitumor activity of a new axially substituted phthalocyanine complex of zirconium(IV) with citric acid. Chem. Biodivers. 2004, 1, 862-867. [CrossRef]

40. Szabó, T.; Tombácz, E.; Illés, E.; Dékány, I. Enhanced acidity and pH-dependent surface charge characterization of successively oxidized graphite oxides. Carbon 2006, 44, 537-545. [CrossRef]

41. Henderson, B.W.; Doougherty, T.J. How does photodynamic therapy work? Photochem. Photobiol. 1992, 55, 145-147. [CrossRef]

42. Hanuza, J.; Godlewska, P.; Kadłubański, P.; Ptak, M.; Mączka, M.; Gerasymchuk, Y.S.; Legendziewicz, J. Molecular structure and vibrational properties of pyramidal $\mathrm{MPc}^{+}$phthalocyanine cation in InPcI and LuPc(OAc) complexes. J. Mol. Struct. 2017, 1130, 699-710. [CrossRef]

43. Song, M.; Tahershamsi, L.; Zhao, J.; Zhang, Z.; Grennberg, H. Efficient gelation of graphene oxide aqueous dispersion induced by sonication-promoted Leuckart reaction. ChemNanoMat 2018, 4, 1145-1152. [CrossRef]

44. Pretsch, E.; Clerc, T.; Seibl, J.; Simon, W. Table of Spectral Data for Structure Determination of Organic Compounds, 3rd ed.; Springer-Verlag: Berlin, Germany, 1998; pp. 238-305.

45. Schafer, M.; Drayß, M.; Springer, A.; Zacharias, P.; Meerholz, K. Radical cations in electrospray mass spectrometry: Formation of open-shell species, examination of the fragmentation behaviour in ESI-MSn and reaction mechanism studies by detection of transient radical cations. Eur. J. Org. Chem. 2007, 31, 5162-5174. [CrossRef]

46. Gerasymchuk, Y.; Chernii, V.Y.; Tomachynski, L.A.; Legendziewicz, J.; Radzki, S. Spectroscopic characterization of zirconium(IV) and hafnium(IV) gallatephthalocyanines in monolithic silica gels obtained by sol-gel method. Opt. Mater. 2005, 27, 1484-1494. [CrossRef]

47. Lukowiak, A.; Gerasymchuk, Y.; Wedzynska, A.; Tahershamsi, L.; Tomala, R.; Strek, W.; Piatek, D.; Krona-Glowniak, I.; Speruda, M.; Kedziora, A.; et al. Light-activated zirconium(IV) phthalocyanine derivatives linked to graphite oxide flakes and discussion on their antibacterial activity. Appl. Sci. 2019, 9, 4447. [CrossRef]

48. Güzel, E.; Şaki, N.; Akın, M.; Nebioğlu, M.; Şişman, İ.; Erdoğmuş, A.; Koçak, M.B. Zinc and chloroindium complexes of furan-2-ylmethoxy substituted phthalocyanines: Preparation and investigation of aggregation, singlet oxygen generation, antioxidant and antimicrobial properties. Synth. Met. 2018, 245, 127-134. [CrossRef]

(C) 2019 by the authors. Licensee MDPI, Basel, Switzerland. This article is an open access article distributed under the terms and conditions of the Creative Commons Attribution (CC BY) license (http://creativecommons.org/licenses/by/4.0/). 